\title{
Absolute Isotopic Abundance Ratios and the Atomic Weight of a Reference Sample of Chromium
}

\author{
William R. Shields, Thomas J. Murphy, Edward J. Catanzaro, and Ernest L. Garner \\ Institute for Materials Research, National Bureau of Standards, Washington, D.C.
}

(December 28, 1965)

\begin{abstract}
Absolute values have been obtained for the isotopic abundance ratios of a reference sample of chromium, using surface emission mass spectrometry. Samples of known isotopic composition. prepared from nearly pure separated chromium isotopes, were used to calibrate the mass spectrometers. The resulting absolute values are $\mathrm{Cr}^{50} / \mathrm{Cr}^{52}=0.051859 \pm 0.000100, \mathrm{Cr}^{53} / \mathrm{Cr}^{52}=0.113386 \pm 0.000145$, $\mathrm{Cr}^{54} / \mathrm{Cr}^{52}=0.028222 \pm 0.000059$, yielding an atomic weight $\left(\mathrm{C}^{12}=12\right)$ of $51.99612 \pm 0.00033$. The indicated uncertainties are overall limits of error based on 95 percent confidence limits for the mean and allowances for effects of known sources of possible systematic error.
\end{abstract}

Key Words: Chromium, atomic weight, isotopic abundances, absolute ratios.

\section{Introduction}

The NBS is conducting a long term program of physical atomic weight determinations, using solidsource mass spectrometry. Previous determinations include silver [1], chlorine [2], copper [3], and bromine [4]. The present work extends the study to chromium.

Recently Flesch et al., [5], published what were purported to be absolute measurements of the chromium isotope ratios. Because of analytical problems they were unable to calibrate their mass spectrometer directly with mixtures of separated chromium isotopes and resorted to indirect calibration, using mixtures of separated nitrogen isotopes. Unfortunately this procedure makes the assignment of the word "absolute" to their results highly questionable.

In the present study, both mass spectrometers used were calibrated for bias by the use of samples of known isotopic composition, prepared from nearly pure separated chromium isotopes. The measured biases were then used to obtain the absolute chromium isotope ratios of a reference sample of commercial chromium. The atomic weight was then calculated, using masses from Mattauch et al., [6].

In this laboratory considerable effort has been expended in the design of collectors and the modification of recorder systems to insure that any biases from these components are constant. The only "random" bias is due to the mass-dependent fractionation of the isotopes during ionization, and this bias is independent of the isotopic composition of the samples. Thus, for each instrumental system used in this study, a single mass-dependent bias correction factor is determined and is valid over the entire range of isotopic compositions measured.

The calibration samples were prepared by mixing aliquots of $\mathrm{Cr}^{50}$ and $\mathrm{Cr}^{54}$ separated isotope solutions.
The use of the two extreme-mass isotopes gives the maximum sensitivity for determining the bias in the source region of a mass spectrometer. Had synthetic mixtures approximating natural chromium isotope composition been used for the calibrations, it would not have been necessary to make corrections for amplifier attenuators, but the propagation of isotopic composition uncertainty involved in mixing all four separated chromium isotope solutions and the fact that the two extreme-mass isotopes are both minor in natural chromium, would have made the bias determinations less accurate.

The fact that each instrument used requires a single correction factor for source discrimination has been demonstrated by numerous analyses of many different uranium isotope standards. However, the assumption was retested in this study by applying the correction factors determined by the unnatural mixes to the analyses of two "natural" synthetic mixes and comparing the experimental results with the theoretical values.

\section{Experimental Procedure}

\subsection{Mass Spectrometry}

The isotopic measurements were made with two different, single-focusing solid-source mass spectrometers. One instrument (MS-2) has a 6-in. radius of curvature $60^{\circ}$ analyzer tube and $48^{\circ}$ sector magnet; the other has a 12 -in. radius of curvature $68^{\circ}$ analyzer tube and $60^{\circ}$ sector magnet. The electronic components and source and collector design are basically the same in both instruments. Surface ionization from single-filament platinum-ribbon sources was used. Triple filament sources (thermal ionization) 
could not be used because they had large $\mathrm{Cr}^{+}$background signals which would have made it impossible to analyze accurately the separated isotopes. Ion currents were measured by means of a vibrating reed electrometer with an expanded-scale recorder. Ratios were measured by varying the magnetic field at constant ion-accelerating voltage.

The chromium was deposited on the sample filament in the form of dilute nitric acid $(1+99)$ solutions of chromium nitrate. One drop of solution, containing approximately $0.06 \mathrm{mg} \mathrm{Cr}(3 \mathrm{mg} \mathrm{Cr} / \mathrm{ml})$, was deposited on the filament and dried with a heat lamp and an electrical current which was slowly increased to $\sim 2.2 \mathrm{~A}$. After this procedure the heat lamp and current were turned off and one drop 10 percent $\mathrm{HNO}_{3}$ or distilled water was placed over the dried sample on the filament. The solution was then redried in the same manner as above. The drop of acid or water served to spread the sample more evenly over the filament surface. No difference was noted between the efficiency of the two reagents; the acid was used in the analyses performed on one mass spectrometer (MS-2) and the water on the other (MS-4).

In the mass spectrometer a strict pattern of filament heating was followed and all data were taken on stable or growing signals $\left(3-4 \times 10^{-12} \mathrm{~A}, \mathrm{Cr}^{52}\right)$ between 37 and 60 min after the filament was turned on. Since the observed ratios varied with time, all analyses which did not follow the normal signal-growth pattern were discarded.

Before being used, all filaments were prebaked in a vacuum and under a potential field, to reduce the possibility of significant chromium background signals from the filament material. Small chromium signals were visible when unbaked filaments were heated to just below their melting point, but no signals were seen for prebaked filaments at the temperatures used in the analyses.

\subsection{Preparation and Chromium Concentration of the Separated Isotope Solutions}

Approximately $2 \mathrm{~g}$ each of electromagnetically separated $\mathrm{Cr}^{50}, \mathrm{Cr}^{52}, \mathrm{Cr}^{53}$, and $\mathrm{Cr}^{54}$ isotopes, in the form of $\mathrm{Cr}_{2} \mathrm{O}_{3}$, were obtained from the Isotopes Division, Oak Ridge National Laboratory of the Union Carbide Nuclear Company. The $\mathrm{Cr}_{2}^{50} \mathrm{O}_{3}$ was designated series LZ, sample 1449A; the $\mathrm{Cr}_{2}^{52} \mathrm{O}_{3}$ was designated series LZ, sample 1450A; the $\mathrm{Cr}_{2}^{53} \mathrm{O}_{3}$ was designated series $\mathrm{LZ}$, sample 1451A; and the $\mathrm{Cr}_{2}^{54} \mathrm{O}_{3}$ was designated series LZ, sample 1452A. The certificate of analysis accompanying each sample indicated a high degree of chemical impurity. The samples were further analyzed by the Spectrochemical Analysis Section of the NBS and the results of these analyses showed the following elements detected at a concentration level of less than 0.01 percent: $\mathrm{Al}, \mathrm{B}, \mathrm{Ca}, \mathrm{Cu}, \mathrm{Fe}$, $\mathrm{Mg}, \mathrm{Mn}, \mathrm{Mo}, \mathrm{Ni}, \mathrm{Pb}, \mathrm{Si}$, and V. No impurities were detected at a higher concentration level. Since the chromium concentrations of the solutions to be prepared were to be determined by reduction of hexavalent chromium with ferrous iron, only vanadium and manganese would interfere in the analyses by being reduced from a higher to a lower oxidation state. These elements were determined quantitatively by emission spectrography. The results showed that the manganese concentration was less than 0.002 percent for each isotope sample and the vanadium concentration was less than 0.005 percent for each sample except the $\mathrm{Cr}^{50}$ sample which contained 0.008 percent V. These concentrations were too low to cause significant error in the chromium determinations, so it was not necessary to further purify the isotope samples.

A 1.3 to $1.5 \mathrm{~g}$ sample of each separated isotope was transferred to a $100 \mathrm{ml}$ beaker and covered with $15 \mathrm{ml}$ of redistilled perchloric acid. The beakers were heated overnight at 140 to $150{ }^{\circ} \mathrm{C}$ to dissolve the chromic oxide and oxidize the $\mathrm{Cr}^{+3}$ to $\mathrm{Cr}^{+6}$. Tests showed that, if the temperature was kept between 140 and $150^{\circ} \mathrm{C}$, only a small amount of chromium would be lost as chromyl chloride and almost all of the chromium would be oxidized to the hexavalent state. The solutions were cooled, diluted with $15 \mathrm{ml}$ of water, and heated on a steam bath until starch iodide paper gave a negative test for chlorine.

The solutions were filtered through sintered glass and transferred to $100 \mathrm{ml}$ volumetric flasks whose necks had been cut off so that only about $1 \mathrm{~cm}$ remained. Enough water was added to bring the final volumes to about $65 \mathrm{ml}$ and the solutions were thoroughly mixed by swirling for several minutes. Each flask was then sealed with a rubber serum septum and allowed to stand overnight in the case of a semimicrobalance to insure thermal equilibrium.

The flasks and contents were weighed on the balance to $\pm 0.02 \mathrm{mg}$. Samples were withdrawn from each flask by inserting a platinum needle, attached to a glass hypodermic syringe with a Kel-F hub, through the rubber septum and withdrawing the desired amount of solution. A second needle which just punctured the septum served as a vent. The weight of the sample withdrawn was determined from the weight of the flask before and after withdrawal of solution.

Four samples each, weighing from 9 to $11 \mathrm{~g}$ and containing 7 to $10 \mathrm{meq}$ (milliequivalent) of chromium, were withdrawn from each solution. Each sample was transferred to a $50 \mathrm{ml}$ Erlenmeyer flask and the syringe and needle were washed with distilled water, the washings also being added to the flask. The volume was adjusted to $10 \mathrm{ml}$ by evaporation. The solution was made alkaline with $10 \mathrm{~N} \mathrm{NaOH}$ solution and $1 \mathrm{ml}$ of 3 percent hydrogen peroxide solution was added to insure complete oxidation to hexavalent chromium. The solution was then heated on a steam bath to destroy the excess hydrogen peroxide.

The chromium concentration of each solution was determined by constant-current coulometric titration with ferrous ions generated at a platinum cathode by electroreduction of ferric ion. The end point was de- 
termined amperometrically. Details of this method are given in Marinenko and Taylor [7].

The accuracy and precision of the chromium concentration measurements were determined by applying the analytical procedure to NBS standard reference material 136b, potassium dichromate, which is known to be $99.977 \pm 0.003$ percent $\mathrm{K}_{2} \mathrm{Cr}_{2} \mathrm{O}_{7}$ [7] based on oxidizing power. Four solutions of this material, in the approximate concentration of the separated isotope solutions, were prepared on a weight basis and the concentration of each solution was calculated as milliequivalents of chromium per gram of solution. Four to six samples were withdrawn from each solution and the chromium in each sample was partially reduced by adding hydrogen peroxide or sulfurous acid. The chromium in each sample was determined by the method described above and the results were compared to the amounts known to be present.

Data resulting from these analyses showed that (a) the average concentration of chromium for each set, as determined by this method, agreed with the calculated concentration to within 0.002 percent, and (b) the standard deviation of an individual determination (17 degrees of freedom) is 0.010 percent for a solution containing $1.0 \mathrm{meq} \mathrm{Cr} / \mathrm{g}$ solution.

The excellent agreement between the analytical and calculated amounts of chromium also prove that the oxidation of trivalent chromium to hexavalent chromium by hydrogen peroxide in alkaline solution is quantitative and that excess hydrogen peroxide is completely destroyed.

TABLE 1. Concentration of chromium isotope solutions

\begin{tabular}{|c|c|c|c|c|}
\hline Soln & Sample No. & Wt. soln & $\mathrm{Cr}$ & $\begin{array}{c}\text { Conc } \mathrm{Cr} \\
\text { meq/g soln }\end{array}$ \\
\hline $\mathrm{Cr}^{50}$ & $\begin{array}{l}\text { A } \\
\text { B } \\
\text { C } \\
\text { D }\end{array}$ & $\begin{array}{c}g \\
10.72803 \\
10.98061 \\
10.72370 \\
10.69936\end{array}$ & $\begin{array}{c}\text { meq } \\
8.085459 \\
8.276915 \\
8.082169 \\
8.064068\end{array}$ & $\begin{array}{r}0.753676 \\
.753776 \\
.753674 \\
.753698 \\
\text { mean } 0.753706^{\text {a }}\end{array}$ \\
\hline $\mathrm{Cr}^{52}$ & $\begin{array}{l}\mathrm{A} \\
\mathrm{B} \\
\mathrm{C} \\
\mathrm{D} \\
\mathrm{E}\end{array}$ & $\begin{array}{l}9.90713 \\
9.44785 \\
9.82398 \\
9.50548 \\
9.06433\end{array}$ & $\begin{array}{l}8.214555 \\
7.830172 \\
8.142790 \\
7.921486 \\
7.513026\end{array}$ & $\begin{array}{r}0.829156 \\
.828778 \\
.828869 \\
.829045 \\
.828856 \\
\text { mean } 0.828941^{a}\end{array}$ \\
\hline $\mathrm{Cr}^{53}$ & $\begin{array}{l}\text { A } \\
\text { B } \\
\text { C } \\
\text { D }\end{array}$ & $\begin{array}{r}10.59417 \\
10.47034 \\
10.83262 \\
9.81393\end{array}$ & $\begin{array}{l}8.202406 \\
8.106043 \\
8.368052 \\
7.608591\end{array}$ & $\begin{array}{r}0.774238 \\
.774191 \\
.774148 \\
.774284 \\
\text { mean } 0.774215^{a}\end{array}$ \\
\hline $\mathrm{Cr}^{54}$ & $\begin{array}{l}\text { A } \\
\text { B } \\
\text { C } \\
\text { D }\end{array}$ & $\begin{array}{r}10.27683 \\
9.51223 \\
9.36201 \\
9.15697\end{array}$ & $\begin{array}{l}9.216768 \\
8.531343 \\
8.398022 \\
8.214576\end{array}$ & $\begin{array}{r}0.896849 \\
.896881 \\
.897032 \\
.897085 \\
\text { mean } 0.896962^{a}\end{array}$ \\
\hline
\end{tabular}

a The uncertainty of the mean at the 95 percent confidence level is $\pm 1.02 \times 10^{-4}$ meq Cr/g soln.

The results of the chromium analyses of the separated isotope solutions are given in table 1. Pooling the results of these four sets of analyses with those of the four sets on the standard material yields a value of $1.05 \times 10^{-4} \mathrm{meq} \mathrm{Cr} / \mathrm{g}$ solution as the standard deviation for an individual determination. The standard error of the mean of four determinations is therefore $0.50 \times 10^{-4} \mathrm{meq} / \mathrm{g}$ solution and that of five determinations is $0.47 \times 10^{-4} \mathrm{meq} / \mathrm{g}$ solution. At the 95 percent confidence level, the uncertainty in the chromium concentrations of the separated isotope solutions is $\pm\left(2.04 \times 0.50 \times 10^{-4}\right)= \pm 1.02 \times 10^{-4} \mathrm{meq} / \mathrm{g}$ solution.

\subsection{Isotopic Analysis of the Separated Isotope Solutions}

Each of the four separated isotope solutions was analyzed four times on each instrument. Sources were dismantled, cleaned and reassembled between the analysis of each solution, as a protection against the possibility of cross contamination from the source parts. Except for the sake of complete security this procedure appears to have been unnecessary. Tests showed that there were no significant differences between the results of an analyses of the $\mathrm{Cr}^{54}$ solution performed on the same source which was previously used for four consecutive analyses of the $\mathrm{Cr}^{50}$ solution and the four $\mathrm{Cr}^{54}$ solution analyses made on a newly cleaned source. No memory effects were visible even in this extreme procedure.

The isotopic compositions of the separated isotopes are given in table 2. They have been corrected for mass spectrometric bias, with changes being negligible after two rounds of iteration. The isotopic compositions reported by ORNL are "Cr50", 95.9 \pm 0.1 atom percent $\mathrm{Cr}^{50}, 3.76 \pm 0.05$ atom percent $\mathrm{Cr}^{52}$, $0.26 \pm 0.05$ atom percent $\mathrm{Cr}^{53}$ and 0.05 atom percent $\mathrm{Cr}^{54}$; "Crr2", 0.01 atom percent $\mathrm{Cr}^{50}, 99.87 \pm 0.02$ atom percent $\mathrm{Cr}^{52}, 0.12 \pm 0.02$ atom percent $\mathrm{Cr}^{53}$ and 0.01 atom percent $\mathrm{Cr}^{54}$; "Cr ${ }^{53}$ ", $<0.05$ atom percent $\mathrm{Cr}^{50}, 3.44 \pm 0.05$ atom percent $\mathrm{Cr}^{52}, 96.4 \pm 0.1$ atom percent $\mathrm{Cr}^{53}$ and $0.18 \pm 0.02$ atom percent $\mathrm{Cr}^{54}$; "Cr ${ }^{54 "}, 0.11$ atom percent $\mathrm{Cr}^{50}, 4.01 \pm 0.05$ atom percent $\mathrm{Cr}^{52}, 1.79 \pm 0.05$ atom percent $\mathrm{Cr}^{53}$ and $94.1 \pm 0.1$ atom percent $\mathrm{Cr}^{54}$. The ORNL limits quoted express the precision of the measurements. From known sources of systematic error, the absolute error is estimated by ORNL to be less than 1 percent.

TABLE 2. Isotopic composition of separated chromium isotopes used in calibration samples

\begin{tabular}{l|r|r}
\hline \multirow{2}{*}{ Isotope } & \multicolumn{2}{|c}{ Isotopic composition (atom percent) } \\
\hline \multirow{3}{*}{$\mathrm{Cr}^{50}$} & & \\
& $\mathrm{Cr}^{50}$ & $95.9118 \pm 0.0101$ \\
& $\mathrm{Cr}^{52}$ & $3.7812 \pm 0.0106$ \\
$\mathrm{Cr}^{53}$ & $0.2582 \pm 0.0014$ \\
$\mathrm{Cr}^{52}$ & $\mathrm{Cr}^{54}$ & $.0487 \pm 0.0017$ \\
& $\mathrm{Cr}^{50}$ & $.0120 \pm 0.0009$ \\
& $\mathrm{Cr}^{52}$ & $99.8664 \pm 0.0032$ \\
& $\mathrm{Cr}^{53}$ & $0.1138 \pm 0.0028$ \\
$\mathrm{Cr}^{53}$ & & $.0078 \pm 0.0012$ \\
& $\mathrm{Cr}^{54}$ & $.0425 \pm 0.0012$ \\
& $\mathrm{Cr}^{52}$ & $3.4658 \pm 0.0088$ \\
& $\mathrm{Cr}^{53}$ & $96.3266 \pm 0.0084$ \\
$\mathrm{Cr}^{54}$ & $\mathrm{Cr}^{54}$ & $0.1651 \pm 0.0020$ \\
& $\mathrm{Cr}^{50}$ & $.1163 \pm 0.0010$ \\
& $\mathrm{Cr}^{52}$ & $4.1066 \pm 0.0123$ \\
& $\mathrm{Cr}^{53}$ & $1.8078 \pm 0.0037$ \\
& $\mathrm{Cr}^{54}$ & \\
\hline
\end{tabular}

a The uncertainties are the 95 percent confidence limits on the ratio determinations. 


\subsection{Preparation of the Calibration Samples and Syn- thetic Mixtures}

Two calibration samples and two synthetic "natural" mixtures were prepared by mixing weighed portions of the separated isotope solutions. The calibration samples (I and II) were prepared from the $\mathrm{Cr}^{50}$ and $\mathrm{Cr}^{54}$ solutions in the approximate ratios $1: 1$ and 2:1, respectively. The synthetic mixtures (III and IV) were prepared by mixing weighed portions of all four of the separated isotope solutions to approximate the isotopic composition of natural chromium.

Each sample was thoroughly mixed and $1 \mathrm{ml}$ of sulfurous acid was added to reduce $\mathrm{Cr}^{+6}$ to $\mathrm{Cr}^{+3}$. Ammonium hydroxide was added to precipitate chromic hydroxide and the solution was filtered. The chromic hydroxide was dissolved in hot dilute $\mathrm{HNO}_{3}$ and the solution was evaporated to near dryness on a steam bath. The residue was taken into solution with 1 percent $\mathrm{HNO}_{3}$ and the volume adjusted so that the chromium concentration was $3 \mathrm{mg} / \mathrm{ml}$. The compositions of the calibration samples (I and II) and the synthetic mixtures (III and IV) are given in table 3 .

TABLE 3. Composition of chromium calibration samples and synthetic mixtures

\begin{tabular}{c|c|c|c|c}
\hline \hline $\begin{array}{c}\text { Mixture } \\
\text { no. }\end{array}$ & $\begin{array}{c}\text { Isotope } \\
\text { Cr }\end{array}$ & Wt. soln & $\begin{array}{c}\text { Conc soln } \\
\text { meq/g soln }\end{array}$ & Cr \\
\hline & & $g$ & & meq \\
I & 50 & 1.00671 & 0.753706 & 0.758763 \\
& 54 & 0.97680 & .896962 & .876152 \\
II & 50 & 1.03063 & .753706 & .776792 \\
& 54 & 0.48383 & .896962 & .433977 \\
III & 50 & .25443 & .753706 & .191765 \\
& 52 & 3.97721 & .828941 & 3.296872 \\
& 54 & 0.49711 & .774215 & 0.384870 \\
IV & 50 & .11805 & .896962 & .105886 \\
& 52 & .18903 & .753706 & .142473 \\
& 53 & 3.52945 & .828941 & 2.925706 \\
& 54 & 0.47447 & .774215 & 0.367350 \\
& & .09084 & .896962 & .081480 \\
\hline
\end{tabular}

\subsection{Isotopic Analyses of the Calibration Samples and Synthetic Mixtures}

Two complete sets of analyses of the calibration samples and synthetic mixtures were made on each instrument. Each set consisted of the following sequence of analyses: Ref., Cal. I; Ref., Cal. II; Syn. III,
Syn. IV, Ref., Cal. I; Ref., Cal. II. All ratios were measured for the reference and synthetic mixtures but only the $\mathrm{Cr}^{50} / \mathrm{Cr}^{54}$ ratio of the calibration samples was measured.

The sources were dismantled, cleaned, and reassembled between each set of analyses but not during any set. The results of the memory tests made during the analyses of the separated isotope solutions showed that the latter precaution was not necessary.

\section{Results and Discussion}

Table 4 summarizes the results for the two calibration samples prepared from the $\mathrm{Cr}^{50}$ and $\mathrm{Cr}^{54}$ separated isotope solutions. The purpose of these samples and analyses was to measure the mass discrimination which resulted from the mode of ionization. The observed ratios have been corrected for the systematic biases of the amplifier attenuators.

Table 5 summarizes the results for the two synthetic mixtures prepared from all four separated isotope solutions. The purpose of these samples and analyses was to demonstrate that the corrections applied to the observed data do, in fact, correct the observed data to absolute. The experimental results (not directly shown in the table) were arrived at by correcting the observed results for attenuator bias, measured by impressing a calibrated voltage on the feedback loop of the amplifier, and mass discrimination, evaluated by the analyses of the calibration samples (table 4).

TABLE 5. Comparison of theoretical and experimental values of "natural" synthetic mixtures

\begin{tabular}{c|c|c|c|c}
\hline \multirow{2}{*}{ Isotope } & \multicolumn{2}{|c|}{ Synthetic mix III } & \multicolumn{2}{c}{ Synthetic mix IV } \\
\cline { 2 - 5 } & Theoretical & Ratio: $\frac{\text { Theor. }}{\text { Exp. }}$ & Theoretical & Ratio: $\frac{\text { Theor. }}{\text { Exp. }}$ \\
\hline 50 & 4.639 & 0.9996 & 3.902 & 0.9990 \\
52 & 83.365 & .9999 & 83.686 & 1.0000 \\
53 & 9.471 & 1.0010 & 10.208 & 1.0003 \\
54 & 2.525 & 0.9995 & 2.203 & 0.9995 \\
\hline
\end{tabular}

These are the only two instrumental corrections necessary. Collector efficiency and linear ohmic

TABLE 4. Determination of mass discrimination in ionization

\begin{tabular}{|c|c|c|c|c|c|c|}
\hline \multirow{3}{*}{ Mass spectrometer } & \multirow{3}{*}{$\begin{array}{l}\text { Determination } \\
\text { number }\end{array}$} & \multicolumn{2}{|c|}{ Calibration mix I } & \multicolumn{2}{|c|}{ Calibration mix II } & \multirow{3}{*}{$\begin{array}{l}\text { Average correction } \\
\text { factor for each } \\
\text { determination } \\
\text { (4 mass units) }\end{array}$} \\
\hline & & \multicolumn{2}{|c|}{ Theor. $\mathrm{Cr}^{50} / \mathrm{Cr}^{54}=0.88476$} & \multicolumn{2}{|c|}{ Theor. $\mathrm{Cr}^{50} / \mathrm{Cr}^{54}=1.82648$} & \\
\hline & & Obs. $\mathrm{Cr}^{50} / \mathrm{Cr}^{54}$ & Ratio: $\frac{\text { Theor. }}{\text { Obs. }}$ & Obs. $\mathrm{Cr}^{50} / \mathrm{Cr}^{54}$ & Ratio: $\frac{\text { Theor }}{\text { Obs. }}$ & \\
\hline MS -2 & $\begin{array}{l}1 \\
2\end{array}$ & $\begin{array}{r}0.91043 \\
.91168\end{array}$ & $\begin{array}{r}0.97180 \\
.97047\end{array}$ & $\begin{array}{l}1.87682 \\
1.87544\end{array}$ & $\begin{array}{r}0.97318 \\
.97390\end{array}$ & $\begin{array}{r}0.97249 \\
.97218\end{array}$ \\
\hline MS-4 & $\begin{array}{l}3 \\
4\end{array}$ & $\begin{array}{l}.90922 \\
.91088\end{array}$ & $\begin{array}{l}.97310 \\
.97133\end{array}$ & $\begin{array}{l}1.87806 \\
1.87555\end{array}$ & $\begin{array}{l}.97254 \\
.97384\end{array}$ & $\begin{array}{l}.97282 \\
.97258\end{array}$ \\
\hline
\end{tabular}


response of the high resistance input resistors were shown to be constant over a much larger range of ion currents by the analyses of many different uranium isotope standards. The $1 / 2$ percent limit of error for "random" (ratio dependent) bias associated with strip-chart recorders was eliminated by the use of expanded scale recorders.

TABLE 6. Corrected isotopic ratios for the reference sample

\begin{tabular}{|c|c|c|c|c|}
\hline $\begin{array}{l}\text { Mass } \\
\text { spectrometer }\end{array}$ & $\begin{array}{l}\text { Determination } \\
\text { number }\end{array}$ & $\mathrm{Cr}^{50} / \mathrm{Cr}^{52 \mathrm{~b}}$ & $\mathrm{Cr}^{53} / \mathrm{Cr}^{52 \mathrm{~b}}$ & $\mathrm{Cr}^{54} / \mathrm{Cr}^{52 \mathrm{~b}}$ \\
\hline $\begin{array}{l}\text { MS-2 } \\
\text { MS-4 }\end{array}$ & $\begin{array}{l}1 \\
2 \\
3 \\
4\end{array}$ & $\begin{array}{r}0.051880 \\
.051898 \\
.051828 \\
.051830\end{array}$ & $\begin{array}{r}0.113416 \\
.113415 \\
.113319 \\
.113393\end{array}$ & $\begin{array}{r}0.028218 \\
.028209 \\
.028239 \\
.028220\end{array}$ \\
\hline Mean... & & 0.051859 & 0.113386 & 0.028222 \\
\hline \multirow{2}{*}{\multicolumn{2}{|c|}{$\begin{array}{l}\text { Overall limit of error }{ }^{\mathrm{a}} \text { Uncertainty components: } \\
95 \text { percent confidence limits on ratio determi- } \\
\text { nation. }\end{array}$}} & \pm 0.000100 & \pm 0.000145 & \pm 0.000059 \\
\hline & & & \pm 0.000032 & \pm 0.000019 \\
\hline \multicolumn{2}{|c|}{$\begin{array}{l}\text { Bounds due to possible systematic error in } \\
\text { correction factor. }\end{array}$} & & \pm 0.000043 & \pm 0.000022 \\
\hline \multicolumn{2}{|c|}{ 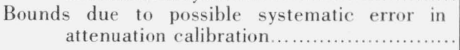 } & $\begin{array}{l} \pm 0.000007 \\
\pm 0.000025\end{array}$ & $\begin{array}{l} \pm 0.000015 \\
\pm 0.000055\end{array}$ & $\begin{array}{l} \pm 0.000004 \\
\pm 0.000014\end{array}$ \\
\hline
\end{tabular}

${ }^{a}$ The overall limit of error is the sum of the 95 percent confidence limits for the ratio determinations and the terms covering effects of known sources of possible systematic error.

${ }^{\mathrm{b}} \mathrm{Each}$ of these ratios is the average of 4 ratios from different runs.
Table 6 gives the corrected chromium isotope ratios as calculated in the four separate determinations, and the average values, with uncertainty components. Using the nuclidic masses given by Mattauch et al. [6], the results yield an atomic weight of 51.99612 \pm 0.00033 on the unified scale $\left(\mathrm{C}^{12}=12\right)$. These calculations are summarized in table 7 .

Flesch et al., [5] report no variations in the isotopic composition of 18 chromite samples from various localities which are the major sources of commercial chromium, so the atomic weight of laboratory chromium should be constant. Svec et al. [8], measured the chromium isotope ratios of a number of secondary chrom-bearing minerals and two meteorite samples but their results left unresolved the question of possible variations in these samples. A further study of natural chromium samples is in progress at this laboratory.

The authors are indebted to Mrs. Martha Darr for the quantitative spectrochemical analyses of the Mn and $\mathrm{V}$ in the chromium isotope samples and to Hsien $\mathrm{H}$. $\mathrm{Ku}$ for the statistical analysis of the experimental data.

TABLE 7. Summary calculations of the atomic weight of chromium in the reference sample

\begin{tabular}{|c|c|c|c|c|c|c|}
\hline & \multirow[b]{2}{*}{ Value } & \multirow[b]{2}{*}{$\begin{array}{l}\text { Overall } \\
\text { limit of } \\
\text { error }^{2}\end{array}$} & \multicolumn{4}{|c|}{ Uncertainty components } \\
\hline & & & $\begin{array}{c}95 \text { percent } \\
\text { confidence } \\
\text { limits on } \\
\text { ratio } \\
\text { determination }\end{array}$ & $\begin{array}{c}\text { Possible } \\
\text { systematic } \\
\text { error in } \\
\text { calibration } \\
\text { factor }\end{array}$ & $\begin{array}{c}\text { Possible } \\
\text { systematic } \\
\text { error in } \\
\text { chemical } \\
\text { analyses }\end{array}$ & $\begin{array}{l}\text { Possible } \\
\text { systematic } \\
\text { error in } \\
\text { attenuation } \\
\text { calibration }\end{array}$ \\
\hline Atomic weight & 51.99612 & \pm 0.00033 & \pm 0.000063 & \pm 0.000135 & \pm 0.000025 & \pm 0.000108 \\
\hline $\begin{array}{c}\text { Nuclidic masses [6] } \\
\left(\mathrm{C}^{12}=12\right) \\
\mathrm{Cr}^{50} \\
\mathrm{Cr}^{52} \\
\mathrm{Cr}^{53} \\
\mathrm{Cr}^{54}\end{array}$ & $\begin{array}{l}49.9460545 \\
51.9405131 \\
52.9406527 \\
53.9388815\end{array}$ & $\begin{array}{r} \pm 0.0000037 \\
\pm .0000032 \\
\pm .0000032 \\
\pm .0000040\end{array}$ & & & & \\
\hline $\begin{array}{l}\text { Atom percent: } \\
\mathrm{Cr}^{50} \\
\mathrm{Cr}^{52} \\
\mathrm{Cr}^{53} \\
\mathrm{Cr}^{54}\end{array}$ & $\begin{array}{r}4.3452 \\
83.7895 \\
9.5006 \\
2.3647\end{array}$ & $\begin{array}{r} \pm 0.0085 \\
\pm .0117 \\
\pm .0110 \\
\pm .0048\end{array}$ & $\begin{array}{r} \pm 0.00233 \\
\pm .00310 \\
\pm .00244 \\
\pm .00154\end{array}$ & $\begin{array}{r} \pm 0.00350 \\
\pm .00172 \\
\pm .00334 \\
\pm .00173\end{array}$ & $\begin{array}{r} \pm 0.00061 \\
\pm .00030 \\
\pm .00058 \\
\pm .00030\end{array}$ & $\begin{array}{r} \pm 0.0021 \\
\pm .0066 \\
\pm .0046 \\
\pm .0012\end{array}$ \\
\hline $\begin{array}{c}\text { Isotopic ratios }{ }^{\text {b }} \\
50 / 52 \\
53 / 52 \\
54 / 52\end{array}$ & $\begin{array}{r}0.051859 \\
.113386 \\
.028222\end{array}$ & $\begin{array}{r} \pm 0.000100 \\
\pm .000145 \\
\pm .000059\end{array}$ & $\begin{array}{r} \pm 0.000029 \\
\pm .000032 \\
\pm .000019\end{array}$ & $\begin{array}{r} \pm 0.000039 \\
\pm .000043 \\
\pm .000022\end{array}$ & $\begin{array}{r} \pm 0.000007 \\
\pm .000015 \\
\pm .000004\end{array}$ & $\begin{array}{r} \pm 0.000025 \\
\pm .000055 \\
\pm .000014\end{array}$ \\
\hline
\end{tabular}

aThe overall limit of error is the sum of the 95 percent confidence limits for the ratio determinations and the terms covering effects of known sources of possible systematic error.

bFrom table 6 .

\section{References}

[1] W. R. Shields, E. L. Garner, and V. H. Dibeler, J. Res. NBS 66A (Phys. and Chem.) No. 1, (1962).

[2] W. R. Shields, T. J. Murphy, E. L. Garner, and V. H. Dibeler, J. Am. Chem. Soc. 84, 1519 (1962).

[3] W. R. Shields, T. J. Murphy, and E. L. Garner, J. Res. NBS 68A (Phys. and Chem.), No. 6, 589 (1964).

[4] E. J. Catanzaro, T. J. Murphy, E. L. Garner, and W. R. Shields, J. Res. NBS 68A (Phys. and Chem.), No. 6, 593 (1964).
[5] G. D. Flesch, H. J. Svec, and H. G. Staley, Geochim. et Cosmochim. Acta 20,300 (1960).

[6] J. H. E. Mattauch, W. Thiele, and A. H. Wapstra, Nuclear Physics 67, 1 (1965).

[7] G. Marinenko and J. K. Taylor, J. Res. NBS 67A (Phys. and Chem.), No. 5, 453 (1963).

[8] H. J. Svec, G. D. Flesch, and J. Capellen, Geochim. et Cosmochim. Acta 26, 1351 (1962).

(Paper 70A2-395) 